\title{
Role of uterine and umbilical artery doppler assessment of the uteroplacental circulation in predicting pre-eclampsia: comparison between different doppler parameters
}

\author{
Vimla Dhakar*, Sabiha Naz
}

Department of Obstetrics and Gynecology, GMCH, Udaipur, Rajasthan, India

Received: 20 August 2017

Accepted: 24 August 2017

\author{
*Correspondence: \\ Dr. Vimla Dhakar, \\ E-mail: vimladhakar1950@gmail.com
}

Copyright: () the author(s), publisher and licensee Medip Academy. This is an open-access article distributed under the terms of the Creative Commons Attribution Non-Commercial License, which permits unrestricted non-commercial use, distribution, and reproduction in any medium, provided the original work is properly cited.

\begin{abstract}
Background: Hypertensive disorders are the common cause of maternal death which affecting nearly 5-10\% of pregnancies all over the world. Pre-eclampsia develop from inadequate trophoblast invasion of the maternal spiral arteries and Doppler values permits non-invasive evaluation of uteroplacental circulation and is of great importance in the management of high risk pregnancies. The aim of the study was to assess the findings of Doppler data in predicting pre-eclampsia and comparison of the efficacy of uterine artery Doppler and umbilical artery Doppler.

Methods: The study comprises of 100 women with high risk pregnancy attending antenatal clinic at Geetanjali Medical College and Hospital, Udaipur were subjected to uterine and umbilical artery Doppler Study. Women with high risk pregnancy between 26-32 weeks of gestation were studied with colour Doppler. This was a prospective study over a period of 1 year from 2015-2016.

Results: The results of the study revealed that 5 out of 100 participants developed pre-eclampsia. Out of different parameters, notch is the best predictor of pre-eclampsia with high sensitivity and highest PPV for uterine artery Doppler and S/D ratio is considered to be best indicator for umbilical artery Doppler. Regarding efficacy, umbilical artery Doppler is more predictive than uterine Doppler.

Conclusions: Doppler study can be used for the prediction of pre-eclampsia to reduce maternal morbidity and mortality.
\end{abstract}

Keywords: Hypertension, Notch, S/D ratio, Pre-eclampsia, Uterine artery Doppler, Umbilical artery Doppler

\section{INTRODUCTION}

Despite of recent advances in antenatal care, preeclampsia remains the major cause of maternal morbidity and mortality. The persistence of high resistance of flow and diastolic notch after 24-26 weeks of gestation provides the rational to investigate the placental circulation of Doppler and to predict pre eclapmsia. ${ }^{1}$ Preeclampsia is heterogenous disorder with variable maternal and fetal complications. The patients who are going to develop pre-eclampsia have progressive increase in systolic to diastolic ratio ( $\mathrm{S} / \mathrm{D}$ ratio), resistive index (RI) and appearance of diastolic notch. ${ }^{2}$

Pre-eclampsia is characterized by an imbalance between prostacycline and thromboxane production as well as failure of second wave trophoblastic invasion of the endomyometrial vasculature. ${ }^{3}$

Any organ may be involved by the disease, but the main organs are the placenta, kidney, brain and eyes. It may be associated with many other signs and symptoms such as 
edema, visual disturbances, headache and epigastric pain. ${ }^{4}$

The result is abnormal utero placental blood flow and this had led to the use of Doppler assessment of uterine and umbilical arteries velocity waveforms as a method of screening for these antenatal complications. In order to avoid serious squeal screening of preeclampsia may allow antenatal surveillance and appropriate timing of foetal delivery and this led to the idea of using uterine and umbilical artery doppler assessment as a screening test for predicticting pre-eclampsia. ${ }^{5}$

The objective of this study was to assess the findings of Doppler data in predicting pre-eclampsia. And to compare the efficacy of uterine artery Doppler and umbilical artery Doppler.

\section{METHODS}

A total of 100 women with high risk pregnancy attending antenatal clinic at Geetanjali Medical College and Hospital, Udaipur were subjected to uterine and umbilical artery Doppler Study. Women with high risk pregnancy between 26-32 weeks of gestation were studied with colour Doppler. This was a prospective study over a period of 1 year from 2015-2016.

Study of umbilical and a uterine artery flow velocity form was done. In both uterine and umbilical artery, S/D ratio and RI (resistance index) were studied. In uterine artery presence and absence of early diastolic notch was noted. In umbilical artery, absent and reversed diastolic flows were studied. Informed consent was obtained from the women who underwent color Doppler study. The outcomes of the pregnancies were evaluated by review of the hospital records after delivery. This study was approved by institutional research committee of the institute.

The accurate gestational age (GA) was estimated by the last menstrual period (LMP) with 28-30 days regular cycles, otherwise, accurate expected date of delivery (EDD) was calculated by ultrasound examination.

These patients were followed up till delivery

\section{Inclusion criteria}

- History of preeclampsia or eclampsia in previous pregnancy

- Preeclampsia or pregnancy-induced hypertension (PIH) current.

\section{Exclusion criteria}

- Patient with congenital anomaly of fetus, multiple gestations
- Patients those who are not getting booked for delivery at Geetanjali Medical College and Hospital in Udaipur

- Patients with unreliable LMP details and not confirmed by early ultrasound.

All the data were entered in Microsoft excel sheet. Statistical analysis was done using diagnostic tests such as sensitivity, specificity and predictive values.

\section{RESULTS}

Out of total study subjects normal Doppler assessment was found in 78 out of 100 and rest of 22 women had abnormal Doppler assessment Table 1 .

Table 1: Combination of uterine and umbilical Doppler values and pre-eclampsia.

\begin{tabular}{|lll|}
\hline Doppler values & $\begin{array}{l}\text { Pre-eclampsia } \\
\text { patients }\end{array}$ & $\begin{array}{l}\text { Total } \\
\text { patients }\end{array}$ \\
\hline Both normal & $1(1.28 \%)$ & $78(100 \%)$ \\
\hline $\begin{array}{l}\text { Normal uterine and } \\
\text { abnormal umbilical }\end{array}$ & $0(0 \%)$ & $8(100 \%)$ \\
$\begin{array}{l}\text { Doppler } \\
\text { Normal umbilical and } \\
\text { abnormal uterine Doppler }\end{array}$ & $2(16.67 \%)$ & $12(100 \%)$ \\
\hline Both abnormal & $2(100 \%)$ & $2(100 \%)$ \\
\hline Total & $5(5 \%)$ & $100(100 \%)$ \\
\hline
\end{tabular}

Overall, out of total women, $12 \%$ had abnormal uterine artery Doppler, $8 \%$ had abnormal umbilical artery Doppler and only $2 \%$ had both abnormal Doppler indices Table 1.

Out of these 22 women with abnormal Doppler, 12 $(54.54 \%)$ had abnormal uterine artery Doppler, 8 (36.36\%) had abnormal umbilical artery Doppler and only $2(9.09 \%)$ had both abnormal Doppler indices Table 1.

Out of total 100 patients, 5 were found to have preeclampsia. Out of these 5 patients with pre-eclampsia, only $1(20 \%)$ had normal Doppler and remaining $4(80 \%)$ had abnormal Doppler Table 1.

Out of these 4 patients with abnormal Doppler, 2 (50\%) had both abnormal indices and $2(50 \%)$ had abnormal uterine Doppler whereas no one had abnormal umbilical artery Doppler Table 1.

Thus, in Table 1, it was observed that when both uterine and umbilical Doppler was abnormal, $100 \%$ of patients developed pre-eclampsia. When both were normal, only $1.28 \%$ developed pre-eclampsia. But with abnormal uterine and normal umbilical Doppler, $16.67 \%$ developed pre-eclampsia and in case of abnormal umbilical Artery Doppler no one developed pre-eclampsia. 
Table 2: Uterine artery Doppler parameters in predicting pre-eclampsia.

\begin{tabular}{|lllll|}
\hline Indices & Sensitivity & Specificity & PPV & NPV \\
\hline S/D ratio & $60 \%$ & $93.70 \%$ & $33.30 \%$ & $97.80 \%$ \\
\hline RI & $40 \%$ & $94.70 \%$ & $28.56 \%$ & $96.77 \%$ \\
\hline Notch & $60 \%$ & $94.74 \%$ & $37.50 \%$ & $97.82 \%$ \\
\hline Combined & $80 \%$ & $89.47 \%$ & $28.57 \%$ & $98.83 \%$ \\
\hline
\end{tabular}

Table 2 reveals in the parameters of uterine artery Doppler in predicting pre-eclampsia, S/D ratio and Notch had sensitivity of $60 \%$ and positive predictive value (PPV) value to be $33.3 \%$ and $37.5 \%$. Specificity of S/D ratio and Notch was $93.7 \%$ and $94.74 \%$ respectively. Thus, Notch as a single parameter is the best indicator with high sensitivity and highest PPV followed by S/D ratio. Since combination of parameter had highest sensitivity of $80 \%$ and PPV to be $28.57 \%$, thus is considered to be good indicator. The sensitivity of RI was $40 \%$ and its PPV was $28.56 \%$. The specificity of all the parameters was above $93 \%$ except combination of parameters $(89.47 \%)$. Negative predictive value (NPV) of all the parameter was in range of $96-99 \%$.

Table 3: Umbilical artery Doppler parameters in predicting pre-eclampsia.

\begin{tabular}{|lllll|}
\hline Indices & Sensitivity & Specificity & PPV & NPV \\
\hline S/D ratio & $40 \%$ & $96.84 \%$ & $40 \%$ & $96.84 \%$ \\
\hline RI & $40 \%$ & $93.68 \%$ & $25 \%$ & $96.74 \%$ \\
\hline Combined & $40 \%$ & $91.58 \%$ & $20 \%$ & $96.67 \%$ \\
\hline
\end{tabular}

Table 3 reveals that in umbilical artery Doppler sensitivity for all indices i.e. S/D ratio, RI and combined parameters were same i.e. $40 \%$. S/D ratio had highest PPV value to be $40 \%$, specificity to be $96.84 \%$. In umbilical artery Doppler RI had specificity of $93.68 \%$ and PPV of $25 \%$ and combination of parameters had specificity of $91.58 \%$ and PPV of $20 \%$. NPV of all the indices was found to be in range of $96-97 \%$. Thus, out of parameters of umbilical artery Doppler $\mathrm{S} / \mathrm{D}$ ratio is considered to be best indicator Table 3 .

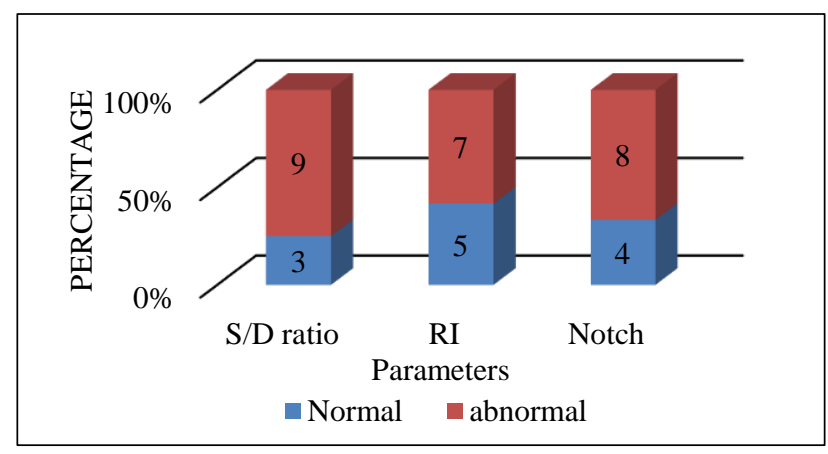

Figure 1: Parameter prediction in abnormal uterine artery Doppler $(n=12)$.

Figure 1 shows that out of total of 22 women with abnormal Doppler, 12 women had found with abnormal uterine artery Doppler, $9(75 \%)$ had abnormal and 3
(25\%) had normal S/D ratio, 7 (58.33\%) had abnormal and $5(41.67 \%)$ had normal RI and $8(66.67 \%)$ had abnormal and $4(33.33 \%)$ had normal Notch.

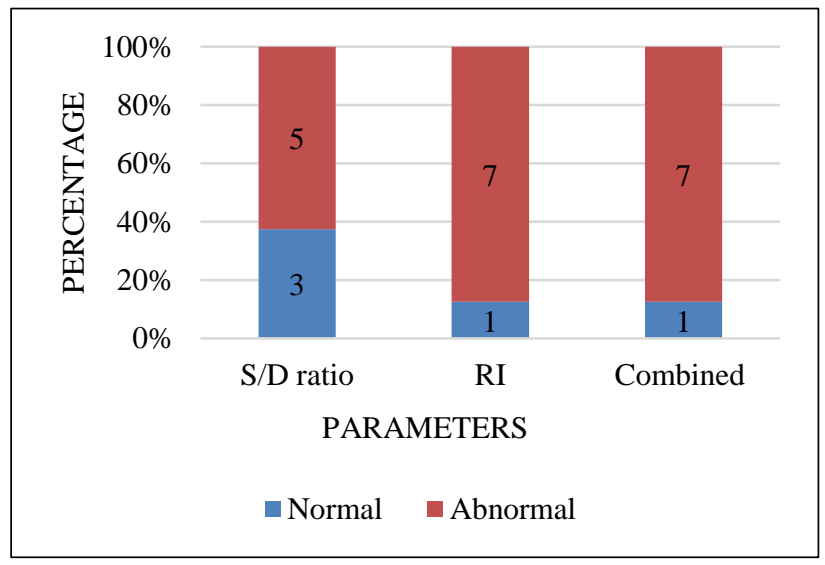

Figure 2: Parameter prediction in abnormal umbilical artery Doppler $(n=8)$.

Figure 2 shows that out of 22 patients with abnormal Doppler, 8 women had found with abnormal umbilical artery Doppler, $5(62.5 \%)$ had abnormal and $3(37.5 \%)$ had normal S/D ratio, $7(87.5 \%)$ had abnormal and 1 $(12.5 \%)$ had normal RI and $7(87.5 \%)$ had abnormal and $1(12.5 \%)$ had normal combined parameters.

\section{DISCUSSION}

In this prospective study in a setup of Geetanjali Medical College and Hospital in Udaipur, which includes women from rural and urban sectors, the predictive values of various Doppler indices have been evaluated.

Out of total sample of 100 women, $78 \%$ found to have normal Doppler and 22\% had abnormal Doppler.

Out of 22 patients with abnormal Doppler,12 (54.54\%) had abnormal uterine artery Doppler, 8 (36.36\%) had abnormal umbilical artery Doppler and only 2 (9.09\%) had both abnormal Doppler indices.

In our study, the prevalence of pre-eclampsia was $5 \%$ which was similar to that quoted by Bewley et al, $(4.6 \%)$ and Jasovic et al (4\%). ${ }^{6,7}$

Out of 12 patients with abnormal uterine artery Doppler, 9 had abnormal S/D ratio and 7 had abnormal RI. ${ }^{8}$ Patients had persistent early diastolic notch, among them, 4 had bilateral and 4 had unilateral.

Out of 8 patients with abnormal umbilical artery Doppler, 5 had abnormal S/D ratio and 7 had abnormal RI. 1 Patients had absent end diastolic flow.

Out of 22 patients, 5 developed pre-eclampsia with sensitivity of $60 \%, 40 \%$ and $60 \%$ for S/D ratio, RI and 
Notch indices for uterine artery which is similar to results obtained by Kurdi et al. ${ }^{8}$

The specificity was between $93-96 \%$ for all indices and PPV was $33.3 \%, 28.6 \%$ and $37.5 \%$ for S/D ratio, RI and Notch respectively. This shows that notch is the best predictor of pre-eclampsia. This is similar to the findings of Bower et al, Divon et al and Antsaklis et al. ${ }^{9-11}$

Out of 8 patients with abnormal umbilical artery, 2 developed pre eclamsia with sensitivity of $40 \%$ for S/D ratio, RI and combined parameters. The specificity was between $93-97 \%$ for all indices and PPV was 40\%, $25 \%$ and $20 \%$ for S/D ratio, RI and combined parameters respectively. This shows that notch is the best predictor of pre-eclampsia.

Mirza et al, did study in 268 women, and there were 57 cases with abnormal Doppler. ${ }^{12}$ Of these, preeclampsia was diagnosed in $14 \%$ cases. Positive predictive values of S/D ratio, RI, and absent end diastolic flow were $40 \%$, $25 \%$ and $100 \%$, respectively. This indicates that umbilical artery Doppler is more predictive than uterine artery Doppler which is found similar to finding of this study.

Thus, it has been observed that umbilical artery Doppler is more predictive than uterine Doppler.

Funding: No funding sources

Conflict of interest: None declared

Ethical approval: The study was approved by the Institutional Ethics Committee

\section{REFERENCES}

1. Moldenhauer JS, Stanek J, Warshak C, Khoury J, Sibai B. The frequency and severity of placental findings in women with pre-eclampsiaare gestational age dependent. Am J Obstet Gynecol. 2003;189:1173-7.

2. Sebire NJ, Goldin RD, Regan L. Term pre-eclampsia is associated with minimal histopathological placental features regardless of clinical severity. J Obstet Gynaecol. 2005;25:117-8.

3. Odegard RA, Vatten LJ, Nilsen ST, Salvesen KA, Austgulen R. Pre-eclampsia and fetal growth. Obstet Gynecol. 2000;96:950-5.
4. Xiong X, Demianczuk NN, Saunders LD, Wang FL, Fraser WD. Impact of pre-eclampsia and gestational hypertension on birth weight by gestational age. Am J Epidemiol. 2002;155:203-9.

5. Xiao R, Sorensen TK, Williams MA, Luthy DA. Influence of pre-eclampsia on fetal growth. J Matern Fetal Neonatal Med. 2003;13:157-62.

6. Bewley S, Copper D, Campbell S. Doppler investigation of uteroplacental blood flow resistance in the second trimester; A screening test for Pre eclampsia and IUGR. $\mathrm{Br}$ J Obstet Gynecol. 1991;98:871-9.

7. Jasovic-Siveska EI, Jasovic VI. Real time ultra sound in the detection of IUGR in pre-eclampsia. Bratisl Lek Lisky. 2008;109(9);405-11.

8. Kurdi W, Campbell S, Aquilina J, England P, Harrington K. the role of colour Doppler imaging of the uterine arteries at 20 weeks of gestation in stratifying antenatal care. Ultrasound Obstet Gynecol. 1988;12:339-45.

9. Bower S, Susan B, Campbell S. Improved prediction of pre-eclampsia by two stage screening of uterine arteries using the early diagnostic notch and colour Doppler imaging. 1993;82:78-83

10. Campbell. New Doppler technique dor assessing uteroplacental blood flow. Lancet. 1983:1;675-7.

11. Antsaklis A, Daskalakis G. The effect of gestational age with placental location on the prediction of preeclampsia. Uterine artery Doppler velocimetry in low risk nulliparous women. Obstet Gynecol. 2000;16:635-9.

12. Mirza FG, Strohsnitter WC, Rivera J, Gyamfibannerman C. Intrauterine growth restriction with abnormal umbilical artery Doppler: a harbinger for pre-eclampsia? J Maternal Fetal Neonatal Med. 2012;25(12):2658-61.

Cite this article as: Dhakar V, Naz S. Role of uterine and umbilical artery doppler assessment of the uteroplacental circulation in predicting preeclampsia: comparison between different doppler parameters. Int J Reprod Contracept Obstet Gynecol 2017;6:4314-7. 